\title{
Preparation and Evaluation of Topical Microemulsion System Containing Metronidazole
}

\author{
Rajarshi Chakraborty ${ }^{1}$, Ratul Bhowmik ${ }^{2}$, Ranajit Nath $^{1 *}$, Sourav Dutta ${ }^{1}$, Apala Chakraborty $^{1}$ \\ ${ }^{1}$ NSHM Knowledge Campus, Kolkata-Group of Institutions, Kolkata, West Bengal, India. \\ ${ }^{2}$ Department of Pharmaceutical Chemistry, SPER, Jamia Hamdard, New Delhi, India. \\ *Corresponding author's E-mail: ranajitnath465@gmail.com
}

Received: 19-07-2021; Revised: 24-09-2021; Accepted: 29-09-2021; Published on: 15-10-2021.

\begin{abstract}
Metronidazole is a synthetic nitroimidazole derived with antimicrobial and anti-inflammatory properties. The aqueous solubility of this drug is poor which results from low bioavailability. Limited effects on the removal of bacteria are shown in the local administration of plain metronidazole. The microemulsion system proves the efficacy of solubility and dissolution improvement of poorly watersoluble drugs such as metronidazole. The objective of this project work is to prepare and evaluate metronidazole containing topical water-in-oil microemulsion and to compare its effectiveness to other commercially available products. In this formulation, tween 80 is used as a surfactant and PEG 400 is used as a co-surfactant. In the oil phase, isopropyl myristate is used. Distilled water is used as the hydrophilic phase. The formulation of metronidazole containing microemulsion was evaluated for physicochemical parameters like $\mathrm{pH}$, viscosity, conductivity, accelerated stability studies. In vitro release study was also performed to evaluate the release kinetics.
\end{abstract}

Keywords: W/O microemulsion; topical application; Skin barriers, Skin permeation.

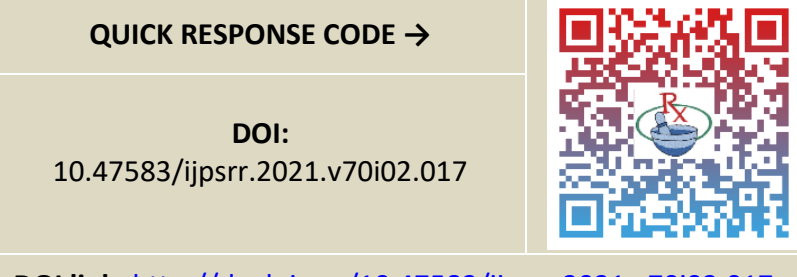

DOI link: http://dx.doi.org/10.47583/ijpsrr.2021.v70i02.017

\section{INTRODUCTION}

$\mathrm{M}$ icroemulsions are transparent, isotropic liquid combinations of water, oil, surfactant/s, and cosurfactant that are thermodynamically stable. Cosurfactant is necessary to reduce the interfacial tension between the water and oil phases ${ }^{1,2,3}$. The droplet size of the dispersed phase in a microemulsion system is exceedingly small (less than 100nm). The microemulsion is an effective technique for increasing medication absorption when applied topically 4,5 . The oil phase, which is made up of unsaturated or saturated fatty acids, acts as a penetration booster. This is the rationale for improved medication absorption in topical applications $6,7,8$. Microemulsions are the most accepted delivery systems due to various advantages such as superior physiochemical stability, increased drug solubility, and a simple manufacturing process ${ }^{9,10}$. Hoar and Schulamn (1943) were the first to report the formation of a single-phase clear solution by titrating a milky emulsion with hexanol. Schulman, Prince, and Stoeckenius created the word "microemulsion" in 1959. In numerous instances, it is also explained and refined. Danielsson and Lindman defined microemulsions in 1981. This definition will be used as a reference in the future ${ }^{11,12}$. The microemulsion is defined as a low viscosity, thermodynamically stable, optically isotropic dispersion of oils (hydrocarbon liquids) and aqueous phases stabilized by interfacial layers of cosurfactant and surfactant molecules ${ }^{13,14,15}$.

Microemulsions are often defined as monodispersed spherical droplets. Droplet sizes range from $10 \mathrm{~nm}$ to 100 $\mathrm{nm}$. The diameter of droplets in a kinetically stable emulsion is more than $500 \mathrm{~nm}^{16,17}$. Because of their small droplet size, microemulsions are ideal carriers for weakly water-soluble medicines ${ }^{18}$. Microemulsions can be created using a variety of water-to-oil ratios and surfactant/s and co-surfactant concentrations. This is a homogeneous system containing liquids of low viscosity. Microemulsions are categorized as water-in-oil and oil-inwater microemulsions based on their composition, surfactant/s, and cosurfactant nature. Polar liquids such as dimethylformamide (DMF), glycerol, glycol, and formamide are used to replace the water in non-aqueous microemulsions ${ }^{19,20,21}$. Microemulsions are thermodynamically stable dispersions made up of an aqueous phase, an oil phase, a surfactant/s, and a cosurfactant that are all single, optically isotropic solutions ${ }^{22}$. A co-surfactant is required to reduce the interfacial tension between the aqueous and oily phases to less than $1 \mathrm{mN} / \mathrm{m}$ (ca. $102-103 \mathrm{mN} / \mathrm{m}$ ), allowing them to form spontaneously without the need for additional external energy, and the formed droplets range in size from a few to two hundred nanometers $(200 \mathrm{~nm}){ }^{23,24,25}$. The structure of a microemulsion can range from spherical droplets to a bicontinuous structure, depending on the nature of the components and the system's composition. They can be of the water-in-oil or oil-in-water variety, with roughly equal proportions of the oil phase and aqueous phase forming a bicontinuous structure ${ }^{26,27}$. Microemulsions are appealing drug delivery devices due to benefits such as increased 
drug solubility, high physicochemical stability, and ease of production. Many researchers attempting to improve the solubility of low-soluble pharmaceuticals have concentrated on the development of lecithin-based microemulsions, and studies have demonstrated that microemulsions can be created utilizing lecithin and a cosurfactant such as short-, medium-, or long-chain alcohols $28,29,30$. Microemulsions were also employed to stabilize active ingredients and improve medicine oral availability. Microemulsions have been demonstrated to be an effective cutaneous delivery mechanism for a variety of active substances used in pharmaceutical and cosmetic applications. Because of the enormous surface area of the internal phase, topical microemulsions allow active molecules to penetrate quickly, and their components lower the barrier property of the stratum corneum ${ }^{31.32,33}$. Microemulsions improve skin absorption as compared to traditional formulations, making them a viable vehicle for transdermal medication administration ${ }^{34,35,36}$.

\section{MATERIALS AND METHODS}

\section{Materials}

Drug: Metronidazole

Oil: Isopropyl myristate

Surfactant: Tween 80

Cosurfactant: PEG400

Hydrophilic phase: Distilled water

Metronidazole (drug) is a gifted product. Isopropyl myristate (oil phase) obtained from LOBA CHEMIE PVT. LTD. Tween 80 (surfactant) is obtained from HIMEDIA Laboratories PVT. LTD. The cosurfactant PEG 400 is obtained from SDFCL.

\section{Drug Profile}

Metronidazole is a synthetic nitroimidazole derivative having antiprotozoal and antibacterial activities.

Mechanism of action: Mechanism of action of the drug metronidazole is not fully elucidated, unionized metronidazole is readily taken up by obligated anaerobic organism and is subsequently reduced by low redox potential electron transport proteins to an active, intermediate product. DNA synthesis and bacterial cell growth have been inhibited by DNA strand break, which is the reason for reduced metronidazole.

\section{Excipient Profile}

\section{Tween 80}

Synonyms: Poly-oxyethylene (20) sorbitan monooleate

Tween 80 acts as a non-ionic surfactant and emulsifier. It is often used in the cosmetics and food industries. In this formulation, Tween 80 or polysorbate 80 acts as a surfactant.

\section{PEG 400}

Synonyms: Polyethylene glycol monooleate

Molecular formula: $\mathrm{C}_{20} \mathrm{H}_{38} \mathrm{O}_{3}$

Molecular weight: $326.5 \mathrm{~g} / \mathrm{mol}$

Density: $1.13 \mathrm{~g} / \mathrm{cm}^{3}$

\section{Isopropyl myristate}

Molecular formula: $\mathrm{C} 17 \mathrm{H} 34 \mathrm{O} 2$

To improve the skin absorption in topical and cosmetic preparation IPM or iso-propyl myristate is used. It also acts as a moisturizer that has polar characteristics. IPM is a well-known skin penetration enhancer. So, in this topical microemulsion formulation as oil phase, IPM is used.

Molecular weight: $270.5 \mathrm{gm} / \mathrm{mol}$

Density: $850 \mathrm{~kg} / \mathrm{m}^{3}$

Boiling point: $167^{\circ} \mathrm{C}$

\section{Pre-formulation Studies}

\section{Solubility study}

By solubility study, using the equilibrium method the components of microemulsion are selected. A known quantity of drug (metronidazole) is dissolved in each of oil (isopropyl myristate), surfactant (Tween 80), co-surfactant (PEG400) using orbital shaker at $100 \mathrm{rpm}$ for 3 days at $25 \pm 1^{\circ} \mathrm{C}$. after then these are centrifuged for 15 minutes at $3000 \mathrm{rpm}$. The supernatant liquid is filtrated through a $0.45 \mu \mathrm{m}$ filter membrane. Using a double beam UV spectrophotometer at $\lambda_{\max } 320 \mathrm{~nm}$ the absorbance of the sample is measured after appropriate dilution of dissolved drug.

\section{Preparation of standard calibration curve of metronidazole in methanol}

Accurately weighed $10 \mathrm{mg}$ of metronidazole was dissolved in methanol and volume was made up to $10 \mathrm{ml}$ with methanol to give the solution $1000 \mu \mathrm{g} / \mathrm{ml}$. Then $1 \mathrm{ml}$ was taken from the solution to a $10 \mathrm{ml}$ volumetric flask and volume was made up to $10 \mathrm{ml}$ with methanol to give the solution a concentration of $100 \mu \mathrm{g} / \mathrm{ml}$. This solution was further diluted and a $10 \mu \mathrm{g} / \mathrm{ml}$ concentration of the solution was prepared. Then the amount of $0.8,1,1.2,1.4$, $1.6 \mathrm{ml}$ was taken from $10 \mu \mathrm{g} / \mathrm{ml}$ solution to $10 \mathrm{ml}$ volumetric flasks and volume was made up with methanol make the concentration of $0.8,1,1.2,1.4,1.6 \mu \mathrm{g} / \mathrm{ml}$, and $0.2,0.4,0.6,0.8,1 \mathrm{ml}$ was taken from $100 \mu \mathrm{g} / \mathrm{ml}$ solution to $10 \mathrm{ml}$ volumetric flasks and volume was made up with methanol to make the concentration of $2,4,6,8,10 \mu \mathrm{g} / \mathrm{ml}$. Absorbance was measured at $320 \mathrm{~nm}$ against a blank (methanol).

\section{Scanning of the drug in phosphate buffer ph 5.5}

$10 \mathrm{mg}$ of drug metronidazole was dissolved in phosphate buffer $\mathrm{pH} 5.5$ in a $10 \mathrm{ml}$ volumetric flask. Using the same solvent volume was made up to $10 \mathrm{ml}$. Taking $1 \mathrm{ml}$ from 
this solution to a $10 \mathrm{ml}$ volumetric flask the volume was made up with the same buffer to get the solution with the concentration $100 \mu \mathrm{g} / \mathrm{ml}$. From this concentration, $10 \mu \mathrm{g} / \mathrm{ml}$ solution was further prepared with dilution. From $10 \mu \mathrm{g} / \mathrm{ml}$ and $100 \mu \mathrm{g} / \mathrm{ml}$ solutions concentration of $0.4,0.6$, $0.8,1,1.2,1.4 \mu \mathrm{g} / \mathrm{ml}$ solutions were prepared. These solutions were scanned at a UV spectrophotometer with $\lambda \max 320 \mathrm{~nm}$.

\section{Drug excipient compatibility study}

Within a range of $400-4000 \mathrm{~cm}^{-1}$ samples were scanned to check drug-excipient interactions with Fourier Transform InfraRed analysis (FTIR). Pure drugs, the mixture of drugs with oil, surfactant, co-surfactant separately, the mixture of drug+surfactant+co-surfactant+oil, and the mixture of excipients are analyzed. Comparing the pure drug FTIR spectrum with that of those mixtures, drug-excipients interaction can be noticed.

\section{Formulation of microemulsion}

To determine the concentration range of components for the microemulsion, the pseudo-ternary phase diagram method was applied at room temperature. The phase diagram was prepared with a ratio of $1: 1$ to $1: 9$ and 2:8 IPM (oil) to surfactant and co-surfactant mixture by weight. Surfactant (Tween80) and co-surfactant (PEG400) ratios were varied from 9:1 to 1:9. In order to establish the microemulsion region border, the mixture of oil, surfactant and co-surfactant was diluted with water dropwise under moderate magnetic stirring and then the mixtures were visually examined for transparency.

The optical changes were observed from turbid to transparent and inversely. The transparent region consisting of a single-phase was determined. For further studies, one microemulsion formulation was selected from this area. The formation of a selected microemulsion took $10 \mathrm{~min}$. This formulation was also be examined for lack of birefringence using a polarized light microscope.

A simple mixing procedure was used to prepare the microemulsion. A drug-loaded microemulsion was formulated by mixing and stirring appropriate quantities of the components and drug in a well-sealed flask until a clear solution was obtained. This process took approximately 45 min and, during this stage, metronidazole was completely dissolved.

\section{Evaluation of microemulsion system}

\section{pH}

At $25 \pm 1^{\circ} \mathrm{C}$ the $\mathrm{pH}$ of the thermodynamically stable emulsion was recorded using a $\mathrm{pH}$ meter (Mettler Toledo, $\mathrm{pH}$ compact, 220). The measurements were wiped out triplicate.

\section{Particle size and zeta potential measurement}

Using Dynamic Light Scattering via ZETASIZERHAS- 3000, the zeta potential of microemulsion was determined.

\section{In vitro release kinetics}

The drug permeability was checked to employ a Franz diffusion cell fitted with a 0.45 micron cellulose membrane pre-hydrated in water at $25 \circ \mathrm{C}$ for twenty-four hours. The receptor compartment was crammed with a $5.5 \mathrm{pH}$ phosphate buffer and therefore the donor compartment was charged with $10 \mathrm{mg}$ of pure drug or $5 \mathrm{ml}$ of the microemulsions. The diffusion medium was continuously stirred at $100 \mathrm{rpm}$ throughout the experiment employing a magnetic stirrer (Remi 2MLH). $2 \mathrm{ml}$ sample was withdrawn for five hours from the receptor compartment and replaced it with the same volume $(2 \mathrm{ml})$ of fresh buffer at the intervals of 15 mints for $1^{\text {st }}$ hour, 30 mints for $2^{\text {nd }}$ hour, and rest were for 1 hour. These samples were diluted with diffusion medium and therefore the absorbance was measured spectrophotometrically at $320 \mathrm{~nm}$. the share cumulative drug release decided for the pure drug also because the formulated microemulsions and data were fitted to Zero order, First order, Higuchi root model, and Korsmeyer-Peppas model as per equations $1,2,3$ and 4 respectively.

Qt represents the cumulative percentage of the drug released in time $\mathrm{t}(\%), \mathrm{Q} 0$ the share of the drug in the formulation at 0 th hour, $\mathrm{k} 0$ represents the zero-order rate constant, the primary order $\mathrm{k} 1$ rate constant $(\mathrm{h}-1) \mathrm{kH}$ Higuchi rate constant (\%h-1/2), where $r$ is the radius of the spherical particle in $\mathrm{cm}, \mathrm{n}$ is Fickian diffusion and $2 \mathrm{n}$ is case II transport which is release exponents.; $a$ and $b$ and represent structural and geometric properties of the microparticles.

\section{Accelerated stability test}

According to $\mathrm{ICH}$ guidelines accelerated stability study was performed in stability chamber (Thermo labs) at $25^{\circ} \mathrm{C} \pm 2^{\circ} \mathrm{C}$ and $10^{\circ} \mathrm{C} \pm 2^{\circ} \mathrm{C}$. In tight screw-capped bottles $5 \mathrm{~mL}$ of formulations were stored for at least 2 months. At 1- and two-month periods samples were withdrawn to check the drug content, phase separation, and the physical appearance of the formulation.

\section{Dilution test}

To check either microemulsion was a clear, less clear, or milky appearance by visual assessment, the formulated microemulsion system was taken for dilution test. The emulsion should be miscible to the liquid which forms the continuous phase (here oil phase). This is the fact which is supported by the dilution test. Dilution with continuous phase, microemulsion should not show any phase separation for at least one hour of storage.

\section{Centrifugation}

Metronidazole drug-loaded microemulsion was centrifuged (Research Centrifuge, R-24, Remi Instruments Limited, Mumbai) to eliminate the metastable system at 4000rpm for 4 hours. 


\section{Visual inspection}

After each addition of water to the mixture of oil, surfactant, and co-surfactant visual inspection was done to identify the sample as microemulsion, emulsion, or gel formation.

\section{Centrifugation}

At 3500rpm for half an hour the formulations were centrifuged and it was checked if there was any phase separation occurred or not. Formulations without any phase separation were taken for the freeze-thaw cycle.

\section{Freeze-thaw cycle}

Between $-10^{\circ} \mathrm{C}$ and $25^{\circ} \mathrm{C}$, three freeze-thaw cycles were done by storing at each temperature for at least 48 hours.

\section{RESULTS AND DISCUSSIONS}

\section{Criteria for component selection}

Metronidazole microemulsion formulation consists of surfactant (Tween 80) and co-surfactant (PEG400) and so the drug metronidazole dissolved in the oil phase. It is an important criterion to check the solubility of the drug in each surfactant, co-surfactant, and particularly in oil. The drug metronidazole is water in the soluble drug so a sufficient amount of oil was required to solubilize the drug and the solubilized form should be maintained. Solubility of metronidazole in tween 80 (surfactant) was $8.45 \pm 0.89$ and in PEG400 (co-surfactant) was $10.88 \pm 0.69$

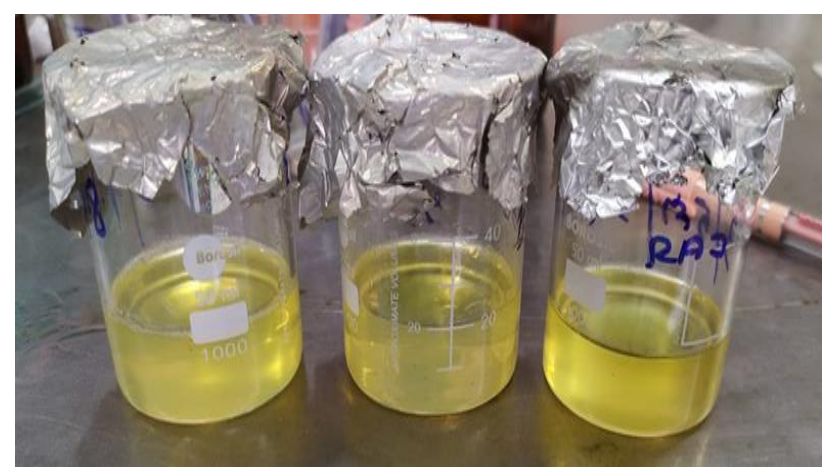

Figure 1: Photo of the Formulations

\section{Drug excipient compatibility study}

Any possible interaction between the drug (metronidazole) and other components (surfactant, cosurfactant, oil) which affects their pharmacological activity was analyzed in a drug-excipient compatibility study. It was confirmed by the FTIR spectrum that none of the components interact with the functional group of the drug. It can be concluded that no major interaction happened between drugs and excipients.

\section{FTIR spectroscopic analysis}

Table 1: Position of IR peaks of the drug, its physical blend, and the formulation

\begin{tabular}{|c|c|}
\hline Range $\left(\mathbf{c m}^{-1}\right)$ & Functional group \\
\hline 2991 & C-H stretching \\
\hline 1600 & C=C stretching \\
\hline 1523 & C=N stretching \\
\hline 1479 & $\mathrm{~N}=\mathrm{O}$ asymmetric \\
\hline $1466-1452$ & $\mathrm{CH}_{2}$ bending vibration \\
\hline $1425-1426$ & C-C stretching \\
\hline 1387 & $\mathrm{CH}_{3}$ asymmetric stretching \\
\hline 1356 & $\mathrm{~N}=\mathrm{O}$ asymmetric stretching \\
\hline $1275-1096$ & C-O stretching \\
\hline 1070 & C-N stretching \\
\hline 711 & $=\mathrm{C}-\mathrm{H}$ bending \\
\hline
\end{tabular}

\section{Pseudo ternary phase diagram}

Pseudo ternary phase diagram for emulsion cannot be constructed in low energy emulsification technique which is known as conventional aqueous titration method, because they are less viscous, monophasic, free-flowing, and clear in appearance. To develop a pseudo ternary phase diagram for the microemulsion system tween 80 and PEG 400 were taken as Smix phase, purified water as aqueous phase, and IPM as oil phase. The shaded area represented the transparent microemulsion region and others are represented the turbid or traditional emulsion region. The unstable and biphasic emulsion was formed when surfactant and co-surfactant concentration was low. Increasing the ratio of Smix, transparent and stable microemulsion was obtained where no phase separation was shown. Oil phase concentration was also important during the formulation period because the concentration of oil is important to solubilize the drug and they also affect phase separation. An increase in oil concentration can be a reason for phase separation. Phase separation can be controlled by the increase in Smix ratio but it is also the reason for gastric irritation and highly viscous formulation and not free-flowing behavior. The optimum ratio of Smix, oil, and water to prepare a microemulsion system can be obtained by a pseudo ternary phase diagram. From this diagram, we can get information on their ratio of preparing thermodynamically stable microemulsion. To check the effectiveness of the formulated microemulsion as a drug delivery system, metronidazole contains microemulsions were prepared and a similar phase diagram was also constructed. These monophasic, clear, and thermodynamically stable microemulsions were further evaluated and the simplest metronidazole contains water in oil microemulsion was identified. 


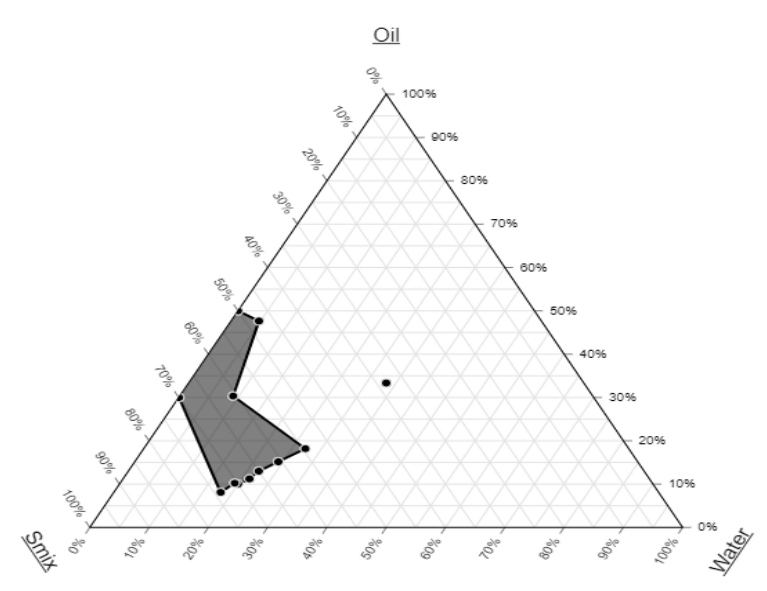

Figure 1: Pseudoternary phase diagrams

\section{Thermodynamic stability study}

pH: $\mathrm{pH}$ of topical water in oil microemulsion formulation with the drug metronidazole was recorded $6.82 \pm 0.08$

Particle size measurement and zeta potential measurement:

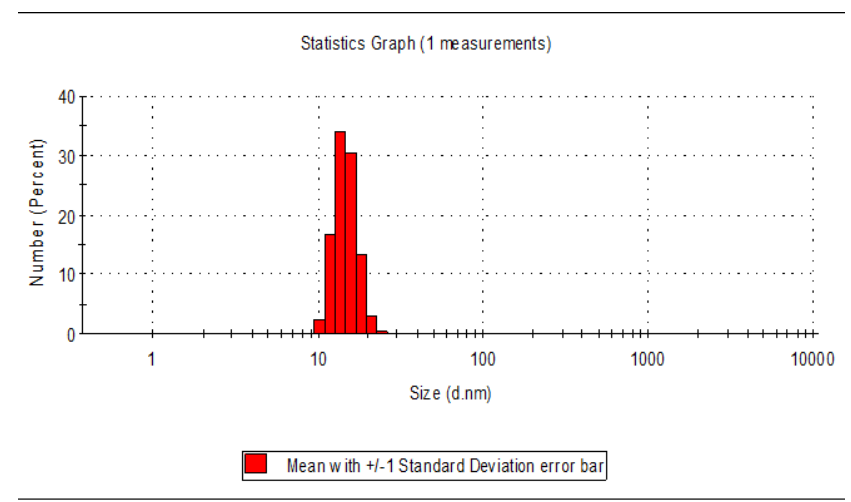

Figure 2: Particle size Measurement and Zeta Potential Measurements

\section{In vitro release kinetics}

After thermodynamic stability tests, it was important to check the release kinetic behavior of the formulation. In vitro release kinetics was performed to check that behavior with the help of the Franz diffusion cell.

Table 2: $R^{2}$ values

\begin{tabular}{|c|c|}
\hline Model name & $\mathbf{R}^{\mathbf{2}}$ value \\
\hline First-order & 0.9446 \\
\hline Zero order & 0.9965 \\
\hline Higuchi & 0.9882 \\
\hline Kerseymeres-Peppa's model & 0.997 \\
\hline Hixon Crowell model & 0.9758 \\
\hline
\end{tabular}

\section{Accelerated stability study}

To check the stability of the topical microemulsion formulation of metronidazole over an extended period the formulations are subjected to accelerated stability study at the end of two months after the physical examinations of the formulation. Microemulsion did not show any kind of cracking and creaming and the formulations remained clear. This was the indication of honest stability.

\section{Physical inspection}

Table 3: Physical inspection

\begin{tabular}{|c|c|}
\hline Parameters & Condition after $\mathbf{2}$ months \\
\hline Clarity & No turbidity \\
\hline Phase separation & No phase separation \\
\hline
\end{tabular}

Drug excipient compatibility testing after $\mathbf{2}$ months:

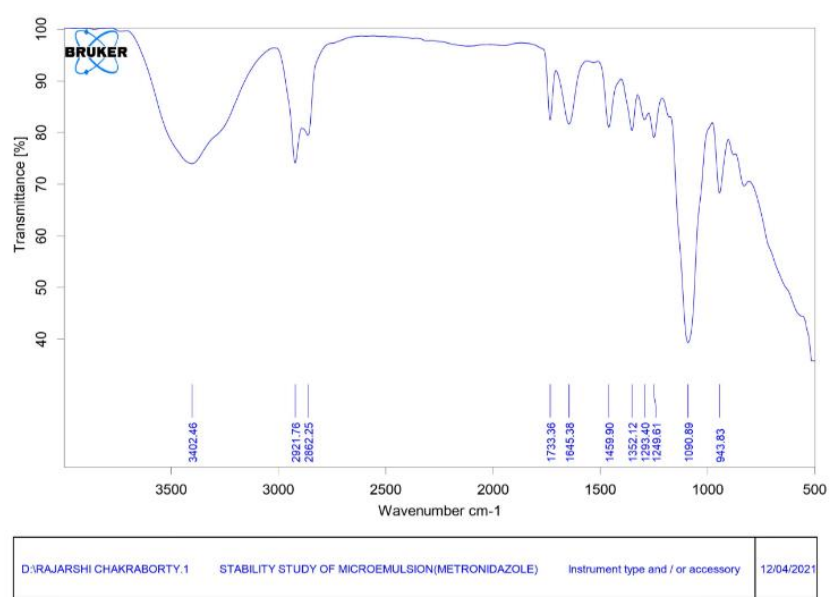

Figure 3: Accelerated stability study

\section{Centrifugation}

After two months of storage centrifugation test was done at $3500 \mathrm{rpm}$ for an hour. No phase separation was shown by the formulation.

\section{Freeze-thaw cycle}

Between $-10^{\circ} \mathrm{C}$ and $25^{\circ} \mathrm{C}$, three freeze-thaw cycles were done by storing at each temperature for at least 48 hours. No changes in physical appearance were shown in these formulations. Phase separations and turbidity were not observed at the end of the experiment. Show it has been proved that the microemulsion system is physically stable in extreme conditions.

Topical water in oil microemulsion formulation of metronidazole was prepared and evaluated. At the very first stage, it was important to determine the ratio of oil and surfactant-cosurfactant to prepare the microemulsion. From the pseudo ternary phase diagram, the proper ratio was found and the formulation was prepared with a specific amount of drug. After formulation microemulsion formulation was sent for the thermodynamic and accelerated stability study. Both results were appreciable and they proved that the formulation was stable and better than the conventional dosage form of the drug. 


\section{CONCLUSION}

Topical water in oil microemulsion formulation of the drug metronidazole was prepared successfully which exhibited greater thermodynamic stability. The formulation also shown higher in vitro release and also had better bioavailability compared to marketed gel formulations. The superiority of topical metronidazole microemulsion formulation was suggested by efficacy evaluation. With the help of the pseudo ternary phase diagram, we get the microemulsion region for the formulation. A solubility study was performed to ensure the solubility of the drug in the surfactant and co-surfactant. From the drug-excipient compatibility study, we ensure that if there was any drug excipient interaction were occurred or not. With the help of a $\mathrm{pH}$ meter, the $\mathrm{pH}$ of the formulation was determined and particle size and zeta potential of the formulation were also measured. Structural changes from water in oil microemulsion to oil in water microemulsion were depicted by conductivity study. An accelerated stability study for the formulation was also performed by storing them for two months. Freeze-thaw cycles and centrifugation of the formulation were performed to ensure the stability of the formulation after two months of storage. No change in physical appearance and no phase separation was shown by the formulation after storing them for an extended period. So, it is also concluded that the formulation had honest stability.

\section{REFERENCES}

1. Kumar B, Jain SK, Prajapati SK. Effect of penetration enhancer DMSO on in-vitro skin permeation of acyclovir transdermal microemulsion formulation. Int J Drug Deliv. 2011;3(1):83-94.

2. Aboofazeli R, Zia H, Needham T. Transdermal delivery of nicardipine: An approach to in vitro permeation enhancement. Drug Deliv J Deliv Target Ther Agents. 2002;9(4):239-47.

3. Carlotti ME, Sapino S, Gallarate M, Peira E, Ugazio E. O/W microemulsions with vanillin as vehicles for antiacne actives: Preparation, characterization, and stability. J Dispers Sci Technol. 2008;29(7):991-8.

4. Chen H, Chang X, Du D, Li J, Xu H, Yang X. Microemulsionbased hydrogel formulation of ibuprofen for topical delivery. Int J Pharm. 2006;315(1-2):52-8.

5. Biggs S. Applications and Fundamentals Comprehensively Linked. Aust J Chem. 2002;55:237.

6. Djekic L, Primorac M. The influence of cosurfactants and oils on the formation of pharmaceutical microemulsions based on PEG-8 caprylic/capric glycerides. Int J Pharm. 2008;352(1-2):231-9.

7. El Maghraby GM. Self-microemulsifying and microemulsion systems for transdermal delivery of indomethacin: Effect of phase transition. Colloids Surfaces B Biointerfaces. 2010;75(2):595-600.

8. Schick MJ, Hubbard AT. Emulsions and Emulsion Stability. Emuls Emuls Stab. 2005;

9. Fanun M. Formulation and characterization of microemulsions based on mixed nonionic surfactants and peppermint oil. J Colloid Interface Sci [Internet]. 2010;343(2):496-503. Available from: http://dx.doi.org/10.1016/j.jcis.2009.12.008

10. Giustini M, Palazzo G, Colafemmina G, Della Monica M, Giomini $M$, Ceglie A. Microstructure and dynamics of the water-in-oil CTAB/n-pentanol/n-hexane/water microemulsion: A spectroscopic and conductivity study. J Phys Chem. 1996;100(8):3190-8.

11. Graca M, Bongaerts JHH, Stokes JR, Granick S. Nanotribology, standard friction, and bulk rheology properties compared for a Brij microemulsion. J Colloid Interface Sci [Internet]. 2009;333(2):628-34. Available from: http://dx.doi.org/10.1016/j.jcis.2009.01.051

12. Transparent Water-in-Oil Dispersions: the Oleopathic Hydro-Micelle. Nature. 1943;152(JULY):102-3.

13. Ma $S$, Chen $F, Y e X$, Dong $Y, X u e ~ Y, X u H$, et al. Intravenous microemulsion of docetaxel containing an anti-tumor synergistic ingredient (Brucea javanica oil): Formulation and pharmacokinetics. Int J Nanomedicine. 2013;8:4045-52.

14. Jadhav K, Shaikh I, Ambade K, Kadam V. Applications of Microemulsion Based Drug Delivery System. Curr Drug Deliv. 2006;3(3):267-73.

15. Malcolmson C, Satra C, Kantaria S, Sidhu A, Lawrence MJ. Effect of oil on the level of solubilization of testosterone propionate into nonionic oil-in-water microemulsions. J Pharm Sci. 1998;87(1):109-16.

16. Malcolmson C, Barlow DJ, Lawrence MJ. Light-scattering studies of testosterone enanthate containing soybean oil/C18:1E10/water oil-in-water microemulsions. J Pharm Sci. 2002;91(11):2317-31.

17. Moniruzzaman M, Kamiya N, Goto M. Ionic liquid based microemulsion with pharmaceutically accepted components: Formulation and potential applications. J Colloid Interface Sci [Internet]. 2010;352(1):136-42. Available from: http://dx.doi.org/10.1016/j.jcis.2010.08.035

18. Moniruzzaman M, Tamura M, Tahara Y, Kamiya N, Goto M. Ionic liquid-in-oil microemulsion as a potential carrier of sparingly soluble drug: Characterization and cytotoxicity evaluation. Int J Pharm [Internet]. 2010;400(1-2):243-50. Available from: http://dx.doi.org/10.1016/j.ijpharm.2010.08.034

19. Tartaro G, Mateos H, Schirone D, Angelico R, Palazzo G. Microemulsion Microstructure ( $\mathrm{s}$ ): A Tutorial Review. nanomaterials. 2020;10(1657):1-40.

20. Narasimha Murthy S, Shivakumar HN. Topical and Transdermal Drug Delivery [Internet]. First Edition. Handbook of Non-Invasive Drug Delivery Systems. Vitthal S. Kulkarni; 2010. 1-36 p. Available from: http://dx.doi.org/10.1016/B978-0-8155-2025-2.10001-0

21. Panapisal V, Charoensri S, Tantituvanont A. Formulation of microemulsion systems for dermal delivery of silymarin. AAPS PharmSciTech. 2012;13(2):389-99.

22. Patel MR, Patel RB, Parikh JR, Solanki AB, Patel BG. Investigating effect of microemulsion components: In vitro permeation of ketoconazole. Pharm Dev Technol. 2011;16(3):250-8. 
23. Paul BK, Moulik SP. MICROEMULSIONS: AN OVERVIEW. 2007;(December 2012):37-41.

24. Shetab Boushehri MA, Dietrich D, Lamprecht A. Nanotechnology as a platform for the development of injectable parenteral formulations: A comprehensive review of the know-hows and state of the art. Pharmaceutics. 2020;12(6):1-53.

25. Shishu G, Rajan S, Kamalpreet. Development of novel microemulsion-based topical formulations of acyclovir for the treatment of cutaneous herpetic infections. AAPS PharmSciTech. 2009;10(2):559-65.

26. Sripriya R, Muthu Raja K, Santhosh G, Chandrasekaran M, Noel $M$. The effect of structure of oil phase, surfactant and co-surfactant on the physicochemical and electrochemical properties of bicontinuous microemulsion. J Colloid Interface Sci. 2007;314(2):712-7.

27. Tanojo $H$, Junginger HE. Skin permeation enhancement by fatty acids. J Dispers Sci Technol. 1999;20(1-2):127-38.

28. Valenta C, Schultz K. Influence of carrageenan on the rheology and skin permeation of microemulsion formulations. J Control Release. 2004;95(2):257-65.

29. Roy R, Bhowmik R, Seth S, Bhattacharyya S, Sengupta S. Computational Repurposing Model of Curcumin as a Drug. Int J Pharm Sci Rev Res. 2021;68(1):165-71.

30. Paul J, Debnath P, Nath R, Bhowmik R, Farheen S. Computer Aided Drug Screening for Lung Infection. Int J Pharm Sci Rev
Res. 2021;68(1):172-6.

31. Kwatra B, Hussain MS, Bhowmik R, Manoharan S. Reviewing Therapeutic and Immuno-Pathological Applications of Vitamins and Carotenoids. Int J Sci Res Sci Technol. 2020;7(4):287-313.

32. Bhowmik R, Roy S, Sengupta S, Sharma S. Biocomputational and Pharmacological Analysis of Phytochemicals From Zingiber officinale (Ginger), Allium sativum (Garlic), and Murrayakoenigii (Curry) Zingiber Officinale (Ginger), Allium sativum (Garlic), and Murrayakoenigii (Curry Leaf). Int J Appl Pharm. 2021;13(5):1-7.

33. Sengupta $S$, Bhowmik R, Acharjee $S$, Sen S. In-Silico Modelling of 1- 3- [ 3- ( Substituted Phenyl) Prop- 2-Enoyl ) Phenyl Thiourea Against Anti-Inflammatory Drug Targets. Biosci Biotechnol Res Asia. 2021;18(2):413-21.

34. Bhowmik R, Nath R, Roy R. Screening of Zinc Database against Streptococcal Cysteine Protease Enzyme for Identification of Novel Group A Streptococcus Inhibitors. J Pharm Res Int. 2021;33(43A):401-12.

35. Kwatra B, Khatun A, Bhowmik R, Rehman S. In silicomodelling of phytochemicals in septic arthritis. Pharma Innov. 2021;10(3):14-21.

36. Kwatra B, Roy R, Bhowmik R, Sengupta S. DRUG REPURPOSING : IN SILICO MODELING OF COVID-19. Res J Life Sci Bioinformatics, Pharm Chem Sci. 2021;7(2):19-40.

Source of Support: The author(s) received no financial support for the research, authorship, and/or publication of this article.

Conflict of Interest: The author(s) declared no potential conflicts of interest with respect to the research, authorship, and/or publication of this article.

For any question relates to this article, please reach us at: editor@globalresearchonline.net New manuscripts for publication can be submitted at: submit@globalresearchonline.net and submit_ijpsrr@rediffmail.com 